\title{
Food and feeding habits of the exotic fish Oreochromis mossambicus (Peters, 1852) from a tropical reservoir of Chalakudy River, Kerala
}

\author{
K. ROSHNI ${ }^{1}$, C. R. RENJITHKUMAR ${ }^{1}$ AND B. MADHUSOODANA KURUP ${ }^{1}$ \\ ${ }^{1}$ School of Industrial Fisheries, Cochin University of Science and Technology, Kochi - 682 016, Kerala, India \\ e-mail: roshni.phd@gmail.com
}

\begin{abstract}
The diet composition of the exotic fish, Oreochromis mossambicus (Peters, 1852) was studied in Poringalkuthu Reservoir, Kerala from June 2011 to May 2012. O. mossambicus (2.52 t) forms a regular fishery which indicate that the fish has been established successfully in the reservoir. Gut content analysis revealed detritus to be the dominant food item followed by chlorophyceae, cyanophyceae, bacillariophyceae, zooplankton, plant matter, sand particles, fish parts, insects and miscellaneous items. The present study shows that the species is an omnivore, with a euryphagous feeding habit.
\end{abstract}

Keywords: Chalakudy river, Exotic fish, Gut contents, Oreochromis mossambicus

The study of food and feeding habits of fishes helps to explore their behaviour, habitat use and trophic interactions in aquatic ecosystems (Walters et al., 1997). While dealing with the process of fish invasions, the evaluation of feeding nature and trophic status of fishes are of core concern. Oreochromis mossambicus (Peters, 1852) commonly known as Mozambique tilapia is a medium-sized, bentho-pelagic, mouth brooding cichlid native to the rivers of central and southern Africa (Philippart and Ruwet, 1982; Trewavas, 1982). O. mossambicus is a highly successful invader in fresh and brackishwater ecosystems and is listed among the worst hundred alien species (Lowe et al., 2000). The species is characterised by many ecological adaptive features like broad feeding spectrum, trophic flexibility, acclimatisation to changing and unfavourable aquatic ecological conditions, high fecundity and parental care (Singh and Lakra, 2011) which make the fish invade and establish in any ecosystem where it gets introduced. O. mossambicus was first introduced into Indian waters from Sri Lanka in 1952 and then it was stocked in many south Indian reservoirs for fishery enhancement (Sugunan, 1995). Studies on the dietary characteristics of O. mossambicus have been reported from Indian waters (Aravindan, 1980; Hatikakoty and Biswas, 2003; Ganie et al., 2013; Indira et al., 2013; Singh and Shukla, 2014). In the present study, an effort is made to examine the feeding habits, seasonal variation in diet composition and feeding intensity of $O$. mossambicus in Poringalkuthu Reservoir of Chalakudy River in Kerala.

River Chalakudy is the fifth longest river of Kerala that originates and flows through the southern parts of
Western Ghats, a global biodiversity hotspot (Myers et al., 2000) which sustains a rich ichthyofaunal diversity of nearly 98 species (Biju et al., 2000). The fish samples were collected from June 2011 to May 2012 from the fish landings of Poringalkuthu Reservoir in Chalakudy River on a monthly basis using gillnets. A total of 263 specimens of O. mossambicus (151 males and 112 females) in the length range 140-259 $\mathrm{mm}$ were examined during the study. After recording the length, weight and sex, the fishes were dissected and the guts were preserved in 5\% formalin. The gut contents were identified under a stereomicroscope (x10) and the food items were weighed and counted. The percentage occurrence of various gut contents was analysed following frequency of occurrence method (Hynes, 1950). By visual examination, the percentage volumes of gut contents were estimated using points method (Pillay, 1952). Index of preponderance was used to estimate the dominant food items in the gut (Natarajan and Jhingran, 1962). The feeding intensity during different months was ascertained by classifying the stomachs into full, $3 / 4,1 / 2,1 / 4$ full and empty following points method.

The qualitative estimation of the gut contents (Fig. 1) revealed that $O$. mossambicus in Poringalkuthu Reservoir is an omnivorous feeder, consuming predominantly detritus $(35 \%)$, chlorophyceae $(33 \%)$, bacillariophyceae $(10 \%)$ and cyanophyceae (9\%). Zooplankton (3\%), plant matter $(3 \%)$, sand particles $(2 \%)$, fish parts $(1 \%)$, insects $(1 \%)$ and miscellaneous items $(3 \%)$ were also encountered as food items in smaller quantities. Detritus in the guts of the fish consisted of a mixture of decayed organic matter, litter and mud. The source of detritus could be heavy rain which introduce different plant 


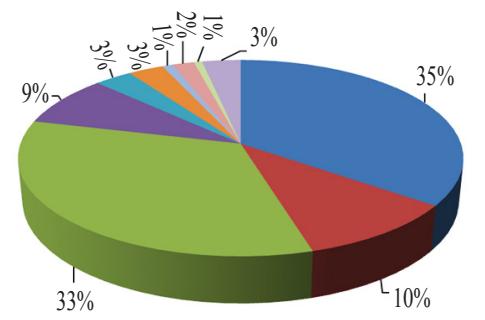

- Detritus

- Bacillariophyceae

- Chlorophyceae

- Cyanophyceae

- Zooplankton

- Plant matter

- Fish parts

- Sand particles

- Insects

- Miscellaneous

Fig. 1. Food compostion of O. mossambicus pooled for different months

material undergoing decomposition. Chlorophyceae in the diet were represented by genera Spirogyra, Ulothrix, Chaetophora, Pediastrum and Chlorella. The major cyanophyceae recorded in the guts of $O$. mossambicus comprised the genera Spirulina, Oscillatoria, Microcystis. Dinophysis, Navicula, Fragilaria and Nitzschia. The fish parts included flesh, scales and larvae and the insects were identified by exoskeleton parts and appendages. Monthly variation in the gut contents indicated that both males and

females have similar feeding habits ingesting the same food items but with slight variation in quantity. Detritus were present in the guts consistently throughout the year which showed highest percentage of occurrence in December (38.81\%) and January (37.21\%) for males and females respectively (Table 1 and 2). A marked increase in the occurrence of bacillariophyceae was seen in pre-monsoon with a peak in March for male fishes and April for females. Chlorophyceae, showed a peak index value for both the sexes in the reservoir in February while its distribution in the fish guts were low in the monsoon months. Cyanophyceae dominated the gut contents in April (pre-monsoon) in males, while females showed its increased occurrence in December. Zooplankton and macrophytes were most abundant in the monsoon season with a slight high proportion of both in females during July and June respectively. Fish parts were observed to have an increasing trend from June to September (monsoon) in males but in females no regular trend was noted even though it was found high in pre-monsoon months. In females during monsoon and pre-monsoon

Table 1. Index of preponderance values of food items in male O. mossambicus in Chalakudy River

\begin{tabular}{|c|c|c|c|c|c|c|c|c|c|c|}
\hline \multicolumn{11}{|c|}{$\%$ composition of food items } \\
\hline Months & Detritus & Bacillariophyceae & Chlorophyceae & Cyanophyceae & Zooplankton & Plantmatter & Fish parts & Sand particles & Insects & Miscellaneous \\
\hline June 2011 & 37.14 & 5.71 & 31.43 & 5.71 & 8.57 & 4.29 & 0.48 & 1.90 & 0.48 & 4.29 \\
\hline July & 37.34 & 6.22 & 31.12 & 5.81 & 8.30 & 4.98 & 0.83 & 1.24 & 0.41 & 3.73 \\
\hline August & 35.29 & 5.04 & 32.77 & 8.40 & 6.30 & 5.04 & 0.84 & 0.84 & 0.42 & 5.04 \\
\hline September & 36.08 & 5.66 & 33.96 & 7.08 & 4.72 & 4.72 & 1.42 & 1.42 & 0.24 & 4.72 \\
\hline October & 35.71 & 6.49 & 32.86 & 7.79 & 4.68 & 4.68 & 1.04 & 2.08 & 0.78 & 3.90 \\
\hline November & 37.50 & 6.25 & 33.33 & 7.81 & 5.21 & 4.17 & 0.52 & 1.56 & 0.52 & 3.13 \\
\hline December & 38.81 & 4.26 & 36.03 & 8.21 & 5.22 & 3.20 & 0.64 & 1.28 & 0.21 & 2.13 \\
\hline January 2012 & 38.19 & 5.73 & 36.28 & 8.35 & 3.82 & 3.82 & 0.48 & 0.95 & 0.24 & 2.15 \\
\hline February & 36.73 & 9.18 & 36.73 & 7.14 & 1.84 & 2.45 & 0.82 & 1.84 & 0.82 & 2.45 \\
\hline March & 36.62 & 11.10 & 33.29 & 8.32 & 3.33 & 2.91 & 0.28 & 1.11 & 0.28 & 2.77 \\
\hline April & 33.86 & 10.58 & 31.75 & 9.26 & 3.17 & 3.97 & 0.53 & 1.59 & 1.06 & 4.23 \\
\hline May & 33.42 & 10.40 & 31.19 & 8.66 & 4.95 & 2.97 & 0.99 & 2.97 & 0.50 & 3.96 \\
\hline
\end{tabular}

Table 2. Index of preponderance values of food items in female $O$. mossambicus in Chalakudy River

\begin{tabular}{|c|c|c|c|c|c|c|c|c|c|c|}
\hline \multicolumn{11}{|c|}{$\%$ composition of food items } \\
\hline Months & Detritus & Bacillariophyceae & Chlorophyceae & Cyanophyceae & Zooplankton & Plant matter & Fish parts & Sand particles & Insects & Miscellaneous \\
\hline June 2011 & 36.91 & 6.04 & 30.20 & 4.03 & 8.05 & 6.04 & 1.34 & 2.68 & 0.67 & 4.03 \\
\hline July & 36.98 & 6.04 & 31.70 & 5.66 & 9.06 & 4.53 & 0.38 & 1.51 & 0.75 & 3.40 \\
\hline August & 36.25 & 5.18 & 33.66 & 9.06 & 5.83 & 3.88 & 0.65 & 1.29 & 0.32 & 3.88 \\
\hline September & 36.43 & 5.10 & 34.61 & 7.29 & 5.46 & 4.37 & 0.36 & 1.64 & 1.09 & 3.64 \\
\hline October & 35.96 & 6.16 & 33.56 & 8.22 & 4.11 & 5.14 & 0.34 & 2.05 & 0.34 & 4.11 \\
\hline November & 36.73 & 5.71 & 33.06 & 7.14 & 5.10 & 4.08 & 1.22 & 2.45 & 1.22 & 3.27 \\
\hline December & 36.31 & 5.30 & 33.28 & 9.08 & 5.30 & 3.63 & 0.91 & 1.82 & 0.61 & 3.78 \\
\hline January 2012 & 37.21 & 6.20 & 36.18 & 9.04 & 4.13 & 2.33 & 0.52 & 1.55 & 0.52 & 2.33 \\
\hline February & 35.18 & 10.05 & 36.18 & 8.04 & 3.02 & 3.02 & 1.01 & 1.01 & 0.50 & 2.01 \\
\hline March & 35.79 & 10.53 & 33.68 & 8.42 & 2.63 & 2.11 & 1.58 & 1.58 & 0.53 & 3.16 \\
\hline April & 34.30 & 10.83 & 32.49 & 9.03 & 2.71 & 2.71 & 1.08 & 2.17 & 1.08 & 3.61 \\
\hline May & 34.62 & 10.58 & 31.73 & 8.41 & 3.61 & 3.61 & 0.72 & 2.40 & 0.72 & 3.61 \\
\hline
\end{tabular}


seasons, the occurrence of sand particles followed a more or less similar pattern and it was found to be high from October to January. Insects represented the least dominant food item which had the highest record in females during monsoon and pre-monsoon and in males the index value of insects was high in pre-monsoon period.

Feeding intensity fluctuated throughout the year showing two peaks in male and female individuals. The degree of fullness of stomach in O. mossambicus during the study period is depicted in Fig. 2 (a,b). Percentage of empty stomachs was higher during June - September and November - February in males and during June - September and January - February in females. The feeding rate was reduced significantly among females during spawning months.

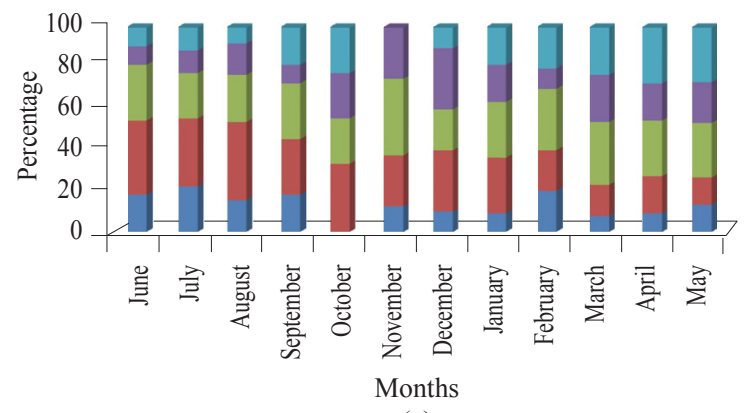

(a) the expansion of $O$. mossambicus (Sreenivasan and Sundarajan, 1967; Jhingran, 1984; Natarajan and Menon, 1989; Sreenivasan, 1996; Lakra et al., 2008; Singh and Lakra, 2011). The orange chromidae, Etroplus maculatus may greatly be affected by tilapia because both the fishes share more or less similar resources (Raghavan et al., 2008). O. mossambicus may cause perilous threat to the existence of the vulnerable species Tor khudree in Periyar Lake, Kerala (Kurup et al., 2006). The proliferation of tilapia may be a reason for the fast decline of T. khudree observed by the local fishers in Poringalkuthu Reservoir, which may gradually displace the golden masheer from the reservoir. O. mossambicus is an important species in the daily landings from the reservoir. The high catch (2.52 t per year) of $O$. mossambicus in Poringalkuthu Reservoir (Roshni et al., 2015) indicates successful establishment of the species in the reservoir and the

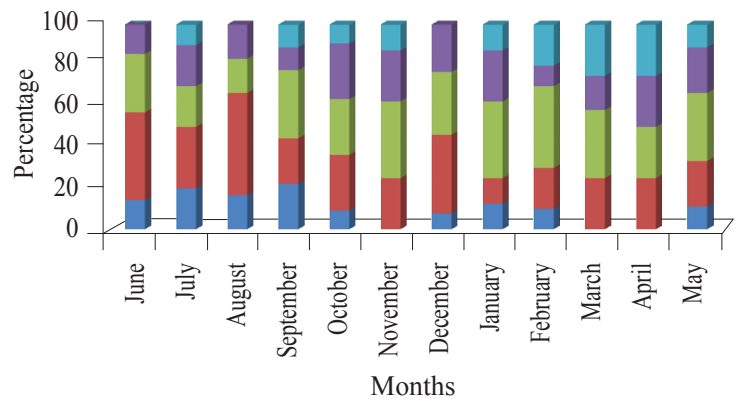

(b)

Fig. 2. Degree of fullness of stomach in O. mossambicus. (a): Males, (b): Females

The results also showed that the fish is a euryphagous feeder with broad and diversified feeding spectrum consuming a variety of food items. Depending upon the availability and food preference, the fish can rapidly switch over among different dietary options (Bowen and Allanson, 1982; McKaye and Marsh, 1983; McKaye et al., 1995). O. mossambicus may possibly be a primarily herbivorous or a detritivorous fish (Bruton and Boltt, 1975; Whitfield and Blaber, 1978; De Silva et al., 1984). The high occurrence of detritus reveals a detritivorous feeding nature of the fish (Doupe and Knott, 2010). A similar result of dominance of detritus in the diet of O. mossambicus was reported in Yamuna River in India (Ganie et al., 2013). The record of sand grains in the gut of the fish is an indication of its probable bottom feeding habits. Occurrence of molluscan shells in the diet also furnishes a possible benthic feeding nature of the fish. Aravindan (1980) and Panikker (2000) reported the omnivorous feeding habit of O. mossambicus which is in favour of the present study.

Several studies were undertaken on the decline of fish species in the natural waters of India due to species may replace the endemic and threatened fish fauna in the far future. Therefore, there is urgent need to initiate continuous monitoring of the population status and range expansion of $O$. mossambicus in the study site and related parts of the river. The investigation on the history of invasion, habitat specificity and eco-biology of the fish is suggested to evaluate its potential impacts on native fishes and for developing effective management strategy.

\section{Acknowledgements}

We thank the Director, School of Industrial Fisheries, Cochin University of Science and Technology (CUSAT) for providing the required facilities, and local fishers of Chalakudy River for assisting the study.

\section{References}

Aravindan, C. M. 1980. Food selection and feeding habits of Tilapia mossambica (Peters) in different ecological habitats. Proc. Ind. Nat. Sci. Acad., B46(1): 54-57.

Biju, C. R., Thomas, K. R. and Ajithkumar, C. R. 2000. Ecology of hill streams of the Western Ghats with special reference 
to fish community, Final report 1996-1999. Project report submitted to Bombay Natural History Society, Bombay, India, $203 \mathrm{pp}$.

Bowen, S. H. and Allanson, B. R. 1982. Behavioural and trophic plasticity of juvenile Tilapia mossambica in utilisation of the unstable littoral habitat. Environ. Biol. Fish., 7: 357-362.

Bruton, M. N. and Boltt, R. E. 1975. Aspects of the biology of Tilapia mossambica (Peters) (Pisces: Cichlidae) in a natural freshwater lake (Lake Sibaya, South Africa). J. Fish Biol., 7: 423-445.

De Silva, S. S., Perera, M. K. and Maitipe, P. 1984. The composition, nutritional status and digestibility of the diets of Sarotherodon mossambicus from nine man-made lakes in Sri Lanka. Environ. Biol. Fish., 11: 205-219.

Doupe, R. G. and Knott, M. J. 2010. Rapid digestion of fish prey by the highly invasive 'detritivore' Oreochromis mossambicus. J. Fish Biol., 76: 1019-1024.

Ganie, M. A., Bhat, M. D., Khan, M. I., Parveen, M., Balkhi, M. H. and Muneer, A. M. 2013. Invasion of the Mozambique tilapia, Oreochromis mossambicus (Pisces: Cichlidae; Peters, 1852) in the Yamuna River, Uttar Pradesh, India, J. Ecol. Nat. Environ., 5(10): 310-317.

Hatikakoty, G. and Biswas, S. P. 2003. Food and feeding habits of Oreochromis mossambicus (Peters) from a sub-tropical environment. J. Inland Fish. Soc. India, 35(2): 57-61.

Hynes, H. B. N. 1950. On the food of the freshwater sticklebacks (Gastrosteus aculeatus and Pygosteus pungitius) with a review of the methods used in the study of food fishes. J. Anim. Ecol., 19: 36-58.

Indira, R., Prabhu, A. J. M. A. and Varadharajan, D. 2013. Food and feeding habits of cichlid fish Oreochromis mossambicus (Peters) from Pichavaram Mangroves, south-east coast of India. Int. J. Phar. Bio. Arch., 4(1): 157-169.

Jhingran, A. G. 1984. Some consideration on introduction of tilapia into inland waters. Bulletin of the Bureau of Fish Genetic Resorces, Central Inland Capture Fisheries Research Institute, Barrack pore, 34 pp.

Kurup, B. M., Radhakrishnan, K. V. and Manojkumar, T. G. 2006. Fish and fisheries of Periyar Lake, Kerala. Indian J. Fish., 53(2): 153-158.

Lakra, W. S., Singh, A. K. and Ayyappan, S. 2008. Fish introductions in India: Status, potential and challenges. Narendra Publishers, New Delhi, India, 303 pp.

Lowe, S., Browne, M., Boudjelas, S. and De Poorter, M. 2000. 100 of the world's worst invasive alien species, A selection from the Global Invasive Species Database. The Invasive Species Specialist Group (ISSG) a specialist group of the Species Survival Commission (SSC) of the World Conservation Union (IUCN), $12 \mathrm{pp}$.

McKaye, K. R. and Marsh, A. 1983. Food switching by two specialised algal-scraping cichlid fishes in Lake Malawi, Africa. Oecologia, 56: 245-248.
McKaye, K. R., Ryan, J. D., Stauffer, J. R. Jr., Lorenzo, J., Lopez, P., Vega, G. I. and van den Berghe, E. P. 1995. African tilapia in Lake Nicaragua: ecosystem in transition. Bioscience, 45: 406-411.

Myers, N., Mittermeier, R. A., Mittermeier, C. G., Da Fonseca, G. A. B. and Kent, J. 2000. Biodiversity hotspots for conservation priorities. Nature, 403: 853-858.

Natarajan, A. V. and Jhingran, A. G. 1962. Index of preponderance - a method of grading the food elements in the stomach analysis of fishes. Indian J. Fish., 8: 54-59.

Natarajan, A. V. and Menon, V. R. 1989. Introduction of exotic fishes in Tamil Nadu. Proceeding of workshop on exotic aquatic species in India. Asian Fisheries Society, Indian Branch, Mangalore, India, p. 62-65.

Panikker, A. C. 2000. Ecological impact of tilapia on the indigenous fish species in two reservoirs of Kerala. Ph. D thesis, University of Kerala, Thiruvanthapuram, $266 \mathrm{pp}$.

Philippart, J. C. and Ruwet, J. C. 1982. Ecology and distribution of tilapias. In: Pullin, R. S. V., Lowe-McConnell, R.H (Eds.), Biology and culture of tilapias. International Center for Living Aquatic Resource Management, Manila, p. 15-59.

Pillay, T. V. R. 1952. A critique of the method of study of food fishes. J. Zoo. Soc. Ind., 42: 185-200.

Raghavan, R., Prasad, G., Ali, A. and Pereira, B. 2008. Exotic fish species in a global biodiversity hotspot: observations from river Chalakudy, part of Western Ghats, Kerala, India. Bio. Invasions., 10: 37-40

Roshni, K., Renjithkumar, C. R. and Kurup, B. M. 2015. Ichthyofaunal diversity in a tropical reservoir of Western Ghats - A biodiversity hotspot, Kerala, India, Proceedings of the Second National Biodiversity Congress, February 2015, p. 263-273.

Singh, A. K. and Lakra, W. S. 2011. Risk and benefit assessment of alien fish species of the aquaculture and aquarium trade in to India. Rev. Aquac., 3: 3-18.

Singh, R. K. and Shukla, S. N. 2014. Ecobiology of Tilapia mossambicus at Rant Talab, Rewa (M.P): A review. Int. $J$. Sci. Res., 3(3): 377-388.

Sreenivasan, A. 1996. Why exotic species?. Fishing Chimes, 16(1): 9-10.

Sreenivasan, A. and Sundarajan, D. 1967. A note on the tilapia fishery of an impoundment in Madras State. Science and Culture, 33: 145-146.

Sugunan, V. V. 1995. Exotic fishes and their role in reservoir fisheries in India. FAO Fisheries Technical Paper No. 345, FAO. Rome.

Trewavas, E. 1982. Tilapias: taxonomy and speciation. In: Pullin R. S. V., Lowe-McConnell, R. H. (Eds.), The biology and culture of Tilapias. International Center for Living Aquatic Resources Management, Manila, p. 3-14. 
Walters, C. V., Christensen and Pauly, D. 1997. Structuring dynamic models of exploited ecosystems from trophic mass-balance assessments. Rev. Fish. Biol. Fish., 7(2): 139-172.
Whitfield, A. K. and Blaber, J. M. 1978. Resource segregation among ilyophagous fish in Lake St. Lucia, Zululand. Environ. Biol. Fish., 3: 293-296. 